\title{
O descaso da administração pública para com os pescadores artesanais e a importância da Educação Ambiental para oferecer alternativas viáveis à manutenção das suas atividades e qualidade de vida
}

\author{
El descaso de la administración pública hacia los pescadores artesanales \\ y la importancia de la Educación Ambiental para ofrecer alternativas \\ viables al mantenimiento de sus actividades y calidad de vida
}

The neglect of the public administration towards the artisanal fishermen and the importance of Environmental Education to offer viable alternatives to the maintenance of their activities and quality of life

\author{
Felipe da Silva Justo ${ }^{1}$ \\ Lúcia de Fátima Socoowski de Anello ${ }^{2}$
}

\begin{abstract}
Resumo
Neste artigo objetivamos tecer considerações sobre as legislações que orientam e regulam a pesca artesanal, no que concerne as autorizações do poder público, a imprescindibilidade da anterior autorização, período de carência para o acesso ao seguro-desemprego em época de defeso, conforme portarias dos órgãos reguladores, confrontando tais burocracias com o desaparelhamento estatal, as restrições legais e com as sanções do poder público. Exsurge a importância da Educação Ambiental, possibilitando uma reintegração destes com o ecossistema regional, bem como para fomentar aos demais cidadãos, a importância da pesca artesanal enquanto atividade financeira e ecológica, já que é possível se alcançar tal objetivo, desde que se proceda com a consciência coletiva de consumo de menor impacto ao ambiente da região e mantenedor das famílias que utilizam meios não agressivos ao ambiente.

Palavras-Chave: Pesca artesanal, Seguro-desemprego, Educação Ambiental.
\end{abstract}

\section{Resumen}

En este artículo pretendemos tejer consideraciones sobre las legislaciones que orientan y regulan la pesca artesanal, en lo que concierne a las autorizaciones del poder público, la imprescindibilidad de la anterior autorización, período de carencia para el acceso al seguro de desempleo en época de veda, conforme a las ordenanzas de los órganos reguladores, enfrentando tales burocracias con el destierro estatal, las restricciones legales y las sanciones del poder público. Destaca la importancia de la Educación Ambiental, permitiendo su reintegración en el ecosistema regional, así como promover a los demás ciudadanos, la importancia de la pesca artesanal como una actividad financiera y ecológica, ya que es posible lograr este objetivo, siempre que el conciencia colectiva del consumo de menor impacto en el medio ambiente de la región y mantenedor de familias que utilizan medios no agresivos.Palabras claves: Pesca artesanal, Seguro de desempleo, Educación ambiental.

Abstract

In this article we intend to make considerations about the laws that guide and regulate the artisanal fishing, regarding the authorizations of the government, the indispensability of the previous authorization, grace period for the access to the unemployment insurance in closed season, according to ordinances of the organs regulators, confronting such bureaucracies with state disrepair, legal restrictions, and the sanctions of public power. It emphasizes the importance of Environmental Education, enabling their reintegration with the regional

\footnotetext{
${ }^{1}$ Mestrando em Educação Ambiental (PPGEA/FURG); Bacharel em Direito (FURG); integrante do Grupo de Pesquisa Cidadania, Direitos e Justiça - CIDIJUS (CNPq). Bolsista da CAPES. felipejusto@ furg.br

2 Doutora em Educação Ambiental. Docente no Programa de Pós-Graduação em Educação Ambiental da Universidade Federal do Rio Grande - PPGEA/FURG. E-mail: luciaanello@ furg.br
} 
ecosystem, as well as to promote to the other citizens, the importance of artisanal fishing as a financial and ecological activity, since it is possible to achieve this objective, provided that the collective awareness of consumption of less impact on the environment of the region and maintainer of families that use non-aggressive means.

Keywords: Artisanal fisheries, Unemployment Insurance, Environmental Education.

\section{Introdução}

A proposta do presente trabalho se origina das demandas surgidas na Defensoria Pública da União, no âmbito de atuação da instituição, em atendimento aos pescadores das cidades de Rio Grande/RS e São José do Norte/RS.

Os pescadores e pescadoras artesanais referidos solicitaram, por meio da Colônia de Pesca à qual são vinculados, o Registro Geral de Pesca - RGP (carteirinha de pesca), pois tal documento é necessário para o pleno exercício da atividade. O Registro Geral de Pesca é elaborado a partir do envio da documentação dos pescadores pelas Colônias de Pesca aos Escritórios Federais de Aquicultura e Pesca - EFAP, que analisa a documentação e instaura o processo administrativo no sistema informatizado, que é remetido à Secretaria Especial de Aquicultura e Pesca - SEAP, a qual possui a atribuição de confeccionar o documento que autoriza e permite a prática de pesca artesanal. Observa-se que sem o documento não existe a possibilidade da prática de pesca legalizada, bem como o documento também é essencial para que seja possível emissão de talão de produtor e para a obtenção do seguro-desemprego, ao quais os pescadores fazem jus durante o período de defeso.

A grande problemática que no caso buscamos demonstrar, refere-se à uma série de ingerências da administração pública, dado o desaparelhamento estatal dos órgãos responsáveis pela plena eficácia da assistência aos pescadores artesanais. Interessante apontar que enquanto os órgãos de auxílio são "desmontados", as instituições fiscalizam e realizam a judicialização da conduta irregular dos referidos pescadores segue em plena atividade, exercitando o poder punitivo estatal em sua forma máxima.

Assim, com o advento de tais fatos, buscamos o apropriado respaldo na Educação Ambiental para questionar meios de apoio aos pescadores artesanais da região, num primeiro momento, apenas analisando as questões jurídicas, nos âmbitos penais e previdenciários, já que concernem imediatamente à vida destes, a seguir, apontando as possíveis atuações da Educação Ambiental, para promover uma integração entre a academia - geradora de saberes teóricos, e os pescadores - que dominam a práxis no que se refere aos conhecimentos da labuta diária. A proposta de aproximar e conectar esses dois saberes distintos é plano de fundo para este trabalho, pois exige um aprofundamento teórico, prático, bem como a junção com a Defensoria Pública da União, entidade que alcança os pescadores e garante que possuam a 
adequada representação frente ao desmonte estatal promovido pelo neoliberalismo que impregna a administração pública.

\section{Pesca Artesanal e Legislação Administrativa Pertinente}

O Registro Geral de Pesca foi instituído pelo Decreto Lei no 221, de 28 de fevereiro de 1967 e ratificado pela Lei no 11.959 , de 26 de junho de 2009, conhecida como a nova lei da pesca. Esse registro é uma forma instrumentalizada, desenvolvida para contribuir com a gestão e o desenvolvimento sustentável da atividade pesqueira, bem como permitindo ao interessado o exercício das atividades de pesca e aquicultura, em toda a sua cadeia produtiva.

O Registro Geral de Pesca consiste em um instrumento do poder executivo que permite legalizar os respectivos usuários para o exercício da atividade pesqueira, com o credenciamento das pessoas físicas ou jurídicas e também das embarcações, para exercerem essas atividades. Assim, o referido documento compreende as informações de todos aqueles que lidam diretamente com a atividade pesqueira, conforme discriminado no Decreto $\mathrm{n}^{\circ}$ $8.425 / 15$, incorporando as seguintes categorias:

Art. $2^{\circ}$ São categorias de inscrição no RGP:

I - pescador e pescadora profissional artesanal - pessoa física, brasileira ou estrangeira, residente no País, que exerce a pesca com fins comerciais de forma autônoma ou em regime de economia familiar, com meios de produção próprios ou mediante contrato de parceria, podendo atuar de forma desembarcada ou utilizar embarcação de pesca com arqueação bruta menor ou igual a vinte;

II - pescador e pescadora profissional industrial - pessoa física, brasileira ou estrangeira, residente no País, que exerce a pesca com fins comerciais, na condição de empregado ou empregada ou em regime de parceria por cotas-partes em embarcação de pesca com qualquer arqueação bruta;

III - armador e armadora de pesca - pessoa física ou jurídica que apresta embarcação própria ou de terceiros para ser utilizada na atividade pesqueira, pondo-a ou não a operar por sua conta;

IV - embarcação de pesca - aquela pertencente a pessoa física ou jurídica, brasileira ou estrangeira, que opera, com exclusividade, em uma ou mais das seguintes atividades:

a) pesca;

b) aquicultura;

c) conservação do pescado;

d) processamento do pescado;

e) transporte do pescado; $\mathrm{e}$

f) pesquisa de recursos pesqueiros;

$\mathrm{V}$ - pescador amador ou esportivo e pescadora amadora ou esportiva - pessoa física, brasileira ou estrangeira, que pratica a pesca com finalidade de lazer ou desporto, com equipamentos ou petrechos previstos em legislação específica, sem fins comerciais;

VI - aquicultor e aquicultora - pessoa física ou jurídica que exerce a aquicultura com fins comerciais;

VII - empresa pesqueira - pessoa jurídica, constituída de acordo com a legislação, que se dedica, com fins comerciais, ao exercício da atividade pesqueira;

$[\ldots]$

IX - aprendiz de pesca - pessoa física com mais de quatorze e menos de dezoito anos que atua de forma desembarcada ou embarcada como tripulante em 
embarcação de pesca, observadas as legislações trabalhista, previdenciária, de proteção à criança e ao adolescente e as normas da autoridade marítima.

Parágrafo único. A pessoa jurídica registrada nas categorias de aquicultor ou de armador de pesca estará automaticamente inscrita na categoria empresa pesqueira.

Como bem demonstrado, o Registro Geral de Pesca é documento essencial para o desempenho da atividade pesqueira, em todas as suas esferas, mas nos atentaremos apenas aos casos de pesca profissional artesanal.

Para a emissão do referido documento, é necessário envio de alguns documentos ao Escritório Federal de Aquicultura e Pesca, que possui sua atribuição amparada no Decreto $\mathrm{n}^{\circ}$ 9.038/17, Anexo V, artigo 44-H para analisar, conferir as documentações, e inserir dados no SisRGP (sistema informatizado, onde os dados são inseridos, após a análise documental), conforme determina o artigo $9^{\circ}$ da Instrução Normativa $n^{\circ}$ 6/18 (BRASIL, 2018):

Art. $9^{\circ}$ Os interessados na manutenção da licença de pescador profissional deverão apresentar, até 31 de dezembro de cada ano-calendário, na Unidade Administrativa do MPA, localizado no Estado de sua residência, os seguintes documentos:

I - no caso de pescador profissional artesanal:

a) relatório de exercício da atividade pesqueira na categoria de pescador profissional artesanal, que poderá ser preenchido diretamente no Sistema Informatizado do Registro Geral da Atividade Pesqueira - SisRGP, disponível no sítio eletrônico http://sisrgp.dataprev.gov.br/rgp/web/sargp;

b) cópia do comprovante de inscrição no:

1. Programa de Integração Social - PIS;

2. Programa de Formação do Patrimônio do Servidor Público - Pasep;

3. Número de Inscrição do Trabalhador - NIT; ou

4. Número de Identificação Social - NIS; e

c) uma foto $3 \times 4 \mathrm{~cm}$ recente, com foco nítido

Entretanto, dado a morosidade para avaliação dos documentos enviados, a inserção de dados para fins de emissão de licença de pescador profissional artesanal no Sistema Informatizado do Registro Geral da Atividade Pesqueira - SisRGP foi suspensa conforme Memorando Circular no 01/2015 - DRPA/SEMOC/MPA (BRASIL, 2015). Com a referida suspensão, para manter a legalidade e evitar um caos por conta da enorme quantidade de pescadores sem registro, foi emitida em 26 de julho de 2017 a Portaria ${ }^{\circ}$ 1.275/17 (BRASIL, 2017), onde:

Art. $1^{\circ}$ Tornar válidos os Registros suspensos ou ainda não analisados com relação ao Relatório de Exercício da Atividade Pesqueira existentes no Sistema de Registro Geral da Atividade Pesqueira- SISRGP, na categoria de pescador profissional, para o pleno exercício da atividade de pesca no País.

Art. $2^{\circ}$ Reconhecer os protocolos de solicitação de Registro iniciais ou de entrega de relatório de manutenção de cadastro na categoria de pescador profissional, devidamente atestado pelo órgão competente, como documentos válidos para o pleno exercício da atividade de pesca. 
Parágrafo único. Os protocolos mencionados no artigo $2^{\circ}$ serão exclusivamente para efeito de comprovação junto aos órgãos de controle e fiscalização da atividade de pesca.

Art. $3^{\circ} \mathrm{O}$ definido nos artigos art. $1^{\circ}$ e $2^{\circ}$ não se aplica para fins de requerimento do seguro-desemprego (seguro-defeso).

Parágrafo único. Para efetivação do recebimento do seguro defeso faz se necessário o atendimento dos requisitos constantes na Lei $n^{\circ} 10.779 / 2003$ e Decreto no 8.424/2015.

(grifo nosso).

Importante observar que apesar do conteúdo narrado na Portaria $\mathrm{n}^{\circ}$ 1.275/17 (BRASIL, 2017), no artigo $3^{\circ}$, onde explicita que a validação das solicitações e renovações não se aplica ao seguro-desemprego (defeso), de forma que, mesmo com a validação, os pescadores artesanais restaram prejudicados, pois apenas a validação não lhes permitiria solicitar o benefício que é essencial à sua subsistência nos meses em que estão legalmente proibidos de praticar a pesca.

Em outubro de 2017, a Portaria $n^{\circ} 1.275 / 17$ (BRASIL, 2017) é revogada pela Portaria $\mathrm{n}^{\mathrm{o}}$ 2.078/ 17 (BRASIL, 2017), mantendo novamente a dificuldade de emissão, renovação e validação dos Registros Gerais de Pesca. Entretanto, em 29 de dezembro de 2017, o Poder Público edita a Portaria n ${ }^{\circ}$ 2.546/17 (BRASIL, 2017), que aprofunda o já apontado na Portaria $\mathrm{n}^{\circ}$ 1.275/17 (BRASIL, 2017), mantendo a inaplicabilidade para solicitação do segurodesemprego (defeso), continuando a prejudicar a vida dos pescadores artesanais:

Art. $1^{\circ}$ Esta Portaria regula a Autorização temporária do Registro Geral da Atividade Pesqueira, categoria Pescador Profissional Artesanal, com vigência até 31 de dezembro de 2018.

Art. $2^{\circ}$ Ficam validados os protocolos de solicitação de Registro Inicial para Licença de Pescador Profissional Artesanal entregues a partir do ano de 2014 como documentos de regularização para o exercício da atividade de pesca.

Art. $3^{\circ}$ Ficam validados os protocolos de entrega de Relatório de Exercício da Atividade Pesqueira - REAP como documentos de regularização das Licenças suspensas, cujo motivo de suspensão foi o descumprimento do Art. $9^{\circ}$ da Instrução Normativa MPA nº6, de 29 de julho de 2012.

$\S 1^{\circ}$ Para efeito desta Portaria, serão considerados os protocolos de entrega de REAP entregues dentro do prazo estabelecido em legislação, os quais ainda não foram devidamente analisados e regularizados pelos Escritórios Federais de Aquicultura e Pesca dos Estados - EFAP's.

$\S 2^{\circ}$ Excluem-se do âmbito desta Portaria:

I - as Licenças que foram suspensas pela falta de apresentação do REAP ou por protocolar o REAP fora do prazo legal;

II - as Licenças já devidamente regularizadas pelos E FA P ' $\mathrm{s}$.

$\S 3^{\circ}$ Os protocolos mencionados nos artigos $1^{\circ}$ e $2^{\circ}$ servirão especialmente para efeito de comprovação junto aos órgãos de controle e fiscalização da atividade de pesca.

Art. $4^{\circ}$ A regularização dada pela presente portaria servirá como comprovante de regularização para fins de recebimento de benefícios previdenciários.

$\S 1^{\circ}$ A SAP notificará os órgãos de fiscalização e de concessão de benefícios de que os protocolos podem ser utilizados como documento comprobatório de regularidade do exercício da atividade de pesca.

$\$ 2^{\circ} \mathrm{O}$ definido no caput não se aplica para fins de requerimento do benefício assistenciário seguro-desemprego (seguro-defeso), o qual se fará necessário o 
atendimento dos requisitos constantes na Lei $\mathrm{n}^{\circ} 10.779$, de 25 de novembro de 2003, e Decreto $n^{\circ} 8.424$, de 31 de março de 2015.

(grifo nosso)

O que se denota das portarias editadas é uma tentativa de manter a regularidade da pesca artesanal, mas sem que se busque a plena efetivação dos direitos desses indivíduos, que acabam convalescendo juridicamente enquanto aguardam que os órgãos procedam com o que é de sua competência. Observa-se que tal dificuldade é relacionada ao alegado desaparelhamento estatal, que busca um Estado "enxuto", mas que carece de eficiência na prática de tal "filosofia" neoliberal.

\section{Pesca Artesanal e a Legislação Previdenciária Pertinente}

Como bem salientado nas portarias citadas anteriormente, o documento de Registro Geral de Pesca é essencial para a para a emissão de talão de produtor e para a obtenção e recebimento do seguro-desemprego (defeso) durante os períodos em que a pesca de determinadas espécies é proibida, conforme preceitua o artigo $2^{\circ}, \S 1^{\circ}$ e $2^{\circ}$ da Lei 10.779 (BRASIL, 2003):

Art. 2o Cabe ao Instituto Nacional do Seguro Social (INSS) receber e processar os requerimentos e habilitar os beneficiários, nos termos do regulamento.

$\S 1$ 1 Para fazer jus ao benefício, o pescador não poderá estar em gozo de nenhum benefício decorrente de benefício previdenciário ou assistencial de natureza continuada, exceto pensão por morte e auxílio-acidente.

$\S 2^{2}$ o o Para se habilitar ao benefício, o pescador deverá apresentar ao INSS os seguintes documentos:

I - registro como pescador profissional, categoria artesanal, devidamente atualizado no Registro Geral da Atividade Pesqueira (RGP), emitido pelo Ministério da Pesca e Aquicultura com antecedência mínima de 1 (um) ano, contado da data de requerimento do benefício;

II - cópia do documento fiscal de venda do pescado a empresa adquirente, consumidora ou consignatária da produção, em que conste, além do registro da operação realizada, o valor da respectiva contribuição previdenciária de que trata o $\S$ 7o do art. 30 da Lei no 8.212, de 24 de julho de 1991, ou comprovante de recolhimento da contribuição previdenciária, caso tenha comercializado sua produção a pessoa física; e

III - outros estabelecidos em ato do Ministério da Previdência Social que comprovem:

a) o exercício da profissão, na forma do art. 1o desta Lei,

b) que se dedicou à pesca durante o período definido no $\S 3$ o do art. 10 desta Lei;

c) que não dispõe de outra fonte de renda diversa da decorrente da atividade pesqueira.

(grifo nosso)

Cada espécie de pescado possui épocas específicas, devidamente reguladas pela Instrução Normativa $n^{\circ} 197 / 08$ (Brasil, 2008), conforme o artigo $1^{\circ}$, $\S 2^{\circ}$ da Lei 10.779 (BRASIL, 2003): O período de defeso de atividade pesqueira é o fixado pelo Instituto 
Brasileiro do Meio Ambiente e dos Recursos Naturais Renováveis - IBAMA, em relação à espécie marinha, fluvial ou lacustre a cuja captura o pescador se dedique.

Assim, como bem disciplinado pela legislação, o pescador artesanal fica impedido de exercer outras atividades laborativas, sob pena de perder a condição de segurado especial, conforme leitura do parágrafo do $\S 4$ “ "Somente terá direito ao seguro-desemprego o segurado especial pescador artesanal que não disponha de outra fonte de renda diversa da decorrente da atividade pesqueira".

Como se verifica da legislação mencionada, é impossível que os pescadores artesanais recebam o seguro-desemprego sem a emissão do Registro Geral de Pesca, que segundo o Escritório Especial de Aquicultura e Pesca, está suspensa por conta de necessidade atualização do sistema informatizado. Em que pese os problemas técnicos que a administração pública alegue possuir, em hipótese alguma isso deveria obstar que os pescadores artesanais recebessem o benefício, que é essencial a sua subsistência.

Nesse sentido, temos uma restrição absoluta, uma vez que a classe pesqueira está restrita de exercer a atividade, de receber o seguro desemprego (defeso) e por fim, resta impedido de exercer outra atividade, pois se o fizer, perderá a condição de pescador artesanal. No advento de exercer a pesca sem atender aos requisitos exigidos em lei, são passíveis de responsabilização civil e penal.

\section{Pesca Artesanal e a Legislação Criminal}

É absolutamente inaceitável que a emissão de um documento, de responsabilidade estatal, obste a remuneração falimentar de centenas de pescadores, que restam impedidos legalmente, de labutarem em atividades diversas, sob pena de responderem criminalmente por isso, caso o façam, incorrendo em estelionato contra o Fundo de Amparo ao Trabalhador FAT, conforme preceitua a legislação penal, parágrafo $3^{\circ}$ do artigo 171, Código Penal (BRASIL, 1941):

Art. 171 - Obter, para si ou para outrem, vantagem ilícita, em prejuízo alheio, induzindo ou mantendo alguém em erro, mediante artifício, ardil, ou qualquer outro meio fraudulento:

Pena - reclusão, de um a cinco anos, e multa, de quinhentos mil réis a dez contos de réis.

$\S 3^{\circ}$ - A pena aumenta-se de um terço, se o crime é cometido em detrimento de entidade de direito público ou de instituto de economia popular, assistência social ou beneficência.

(Grifo nosso)

Observadamente, dado as dificuldades de subsistência, é de extrema ingenuidade supor que esses pescadores, no período em que restaram impossibilitados de receber o seguro- 
desemprego, não tenham exercido outras atividades, para bem de auferirem qualquer renda, no intuito de garantirem a sua subsistência. É importante referir que tal situação decorre única e exclusivamente por culpa da União e seus órgãos, que diante do seu dever funcional, obliteraram-se da responsabilidade que lhes é atribuída, de forma que também cabe a devida penalização por tal descumprimento, pois tal morosidade é condenada pela Constituição Federal (BRASIL, 1988), no seu artigo 50, inciso LXXVIII: “A todos, no âmbito judicial e administrativo, são assegurados a razoável duração do processo e os meios que garantam a celeridade de sua tramitação", assim como o artigo 49 da Lei no 9.784/99 (BRASIL, 1999), que regula os processos administrativos no âmbito da administração pública federal, estabelece o prazo decisório de 30 dias, prorrogável por período igual, totalizando, impreterivelmente, 60 dias para emitir decisão sobre o processo administrativo.

Ressalta-se, ainda, que quaisquer mudanças institucionais não devem configurar motivo para óbice em relação à obtenção dos direitos constitucionalmente estabelecidos do cidadão. O contexto evidenciado demonstra, em termos gerais, grave lesão ao princípio da eficiência, basilar da Administração Pública em geral, porquanto o processo administrativo não se desenvolve de forma tempestiva, causando prejuízo àqueles que necessitaram de providências do ente Federal.

\section{Pesca Artesanal e a Legislação Criminal}

A pesca é uma das atividades humanas mais antigas de extrativismo, praticada pelo homem desde a pré-história, com intuito de obter alimentos necessários à sua subsistência a partir do meio aquático (JUSTO; AMORIM, 2019, p. 4). Mas além da importância para a subsistência humana, a pesca é uma atividade econômica importante, implicando em vária outras atividades complementares, como o transporte, armazenamento, transformação e venda dos produtos da pesca, construção e reparação das embarcações de pesca, construção de artes e utensílios de pesca, gerando renda e empregando pessoas nas atividades indiretas.

Entretanto tal atividade também sofreu influências do advento da modernidade, de forma que a pesca manual, em pequena escala, foi substituída pela pesca industrial, visando o lucro, em detrimento ao meio ambiente, gerando impactos sem precedentes nos ecossistemas marítimos e lacustres. Como exposto por Justo e Amorim (2019, p. 3)

Os pescadores estão se organizando de modo a não sucumbirem enquanto categoria profissional diante da crescente poluição das águas e o consequente declínio do chamado recurso pesqueiro, seja pela pesca predatória, pela pesca industrial, mudanças climáticas, especulação imobiliária em áreas litorâneas, turismo, dificuldade de acesso às políticas públicas e de compreensão e adequação ao 
excessivo e, muitas vezes, contraditório regramento para o setor, além de tantos outros fatores que intervém direta e indiretamente nesta atividade.

Para coibir determinadas práticas predatórias, existem acordos internacionais, como por exemplo, o acordo internacional para regulamentar a caça às baleias azuis, ratificado pelo Brasil e vigente a partir de 1973 (BRASIL, 1973).

O grande problema é a percepção que a espécie humana tem da natureza, em que a sociedade se exclui do ecossistema, sem vinculação à natureza, como se dela não fizesse parte, tal qual aponta, Guimarães $(1995$, p. 12) quando discorre sobre o homem e a natureza:

Nas sociedades atuais o ser humano afasta se da natureza. [...] O ser humano, totalmente desintegrado do todo, não percebe mais as relações de equilíbrio da natureza. Age de forma totalmente desarmônica sobre o ambiente, causando grandes desequilíbrios ambientais [...].

Com essa compreensão do agir dos homens e mulheres da nossa sociedade, baseado no extrativismo e consumo desenfreado, o qual promove um esgotamento dos "recursos", percebeu-se o risco que o planeta, e por consequência, a espécie humana, corria, de forma que novas propostas surgiram, visando a "preservação", mas apenas para garantir o consumo, e através disso, desencadear o aumento das desigualdades, pois apenas uma fração de pessoas usufrui com os lucros que adimplidos nessa exploração desenfreada. Isto por que as formas de poluição são diversas, e cada agente contribui de um modo, nas capacidades que lhe cabem, de forma que é absurdo comparar uma mineradora poluidora com um pequeno pescador que enceta sua atividade em período proibido (defeso): são atividades que poluem e afetam o equilíbrio natural, mas devem ser observadas em perspectivas baseadas na proporcionalidade do dano, como aponta Reigota (2009, p. 50) acerca dessa situação:

Os impactos ambientais que provocamos com o nosso estilo de vida são diferentes e diferenciados e precisam ser enfatizados e não camuflados na afirmativa simplificadora de que "o homem destrói o meio ambiente". (grifo do autor)

Observar-se que a pesca artesanal, tal como é praticada, sem o viés predatório e potencialmente agressivo, que é costumeiro da atividade industrial, onde se utilizam de redes de arrasto que tocam o solo subaquático e danificam a espécies vegetais, além do "naturalizado" descarte dos espécimes menores ou não rentáveis, conquanto a pesca artesanal permita uma maior vinculação do pescador ao ambiente que lhe fornece alimento.

Percebe-se que, enquanto consumo oriundo de extrativismo animal, a pesca artesanal garante um modelo que permite a regeneração das espécies alvo, lesando minimamente (se comparado com a pesca industrial) as demais espécies vegetais e animais, além de garantir a existência de um mercado fomentado no consumo que impacto menos o ambiente e garanta a 
renda para os pequenos produtores e pescadores da região. A grande problemática é garantir que a pesca artesanal receba do Governo Federal o devido tratamento, seja das instituições diretamente conectadas à emissão das autorizações assim como a garantia de sua subsistência nos períodos de proibição regulamentada, pois o que ocorre é uma fragilização das instituições democráticas, onde o órgão que regia as atividades relacionadas à pesca, o Ministério da Pesca e Aquicultura - MPA, foi extinto em 2015, sendo incorporado ao Ministério da Agricultura, Pecuária e Abastecimento - MAPA, tendo sido transferida a competência para fornecer o Registro Geral de Pesca para a Secretaria da Aquicultura e Pesca - SEAP, vinculada ao atual Ministério da Indústria, Comércio Exterior e Serviços - MDIC. Há constantes modificações da estrutura governamental, e no caso em exemplo, tais mudanças fragilizaram um sistema que é já é por si, precário, composto por uma classe trabalhadora humilde e que sofre com toda uma série de intempéries, onde o Estado desumaniza e deixa ao relento da providência, enquanto deveria assumir a sua responsabilidade e garantir aquilo que é previsto em lei.

\section{Considerações}

Como apontado, é possível que por meio da Educação Ambiental, se promova o resgate e a manutenção de toda uma cultura pesqueira, com a adequada integração dos pescadores artesanais à compreensão da sua importância para fim de se manter e garantir um extrativismo com menor índice de danos ao ecossistema lacustre nas cidades de Rio Grande/RS e São José do Norte/RS. Ressalta-se que para além da preservação, é possível uma melhora na qualidade de vida e de renda destes pescadores, uma vez que é possível o desenvolvimento de atividades conexas à pesca, permitindo que mantenham a condição de segurados especiais, auferindo renda mesmo nos períodos de restrição legal. Atividades como o ecoturismo, apoio à pesquisa, bem como acesso a cursos e palestras que promovam a troca de experiências entre a práxis dos pescadores e a teoria acadêmica, que contumazmente observa de forma distanciada o desenrolar dos fatos. Assim, utilizando os meios pedagógicos, nos âmbitos escolares, acadêmicos, se possível, políticos, compreende-se que, como aponta Reigota (1996, p. 18 e 19)

A educação ambiental deve orientar-se para a comunidade, para que ela possa [...] auxiliar e incentivar o cidadão e a cidadã a participarem da resolução dos problemas e da busca de alternativas no seu cotidiano de realidades específicas [..] influir decisivamente para isso, quando forma cidadãos e cidadãs conscientes dos seus direitos e deveres. Tendo consciência e conhecimento da problemática global e 
atuando na sua comunidade e vice-versa haverá uma mudança na vida cotidiana que, se não é de resultados imediatos, visíveis, também não será sem efeitos concretos.

Importante salientar que este trabalho apenas capta e elenca as dificuldades, seja no viés da administração pública, seja na questão previdenciária ou criminal, que afetam os e as pescadoras artesanais da região, objetificando propor meios de conectar e entrelaçar os ideais ambientais críticos com a melhora da qualidade de vida e de renda destes e suas famílias.

Assim, resta claro, conforme explicita Müller (2000), ao demonstrar que os objetivos da Educação Ambiental são

Fazer com que os indivíduos ou grupos sociais tomem maior consciência dos problemas e das características ambientais, locais e globais;

Contribuir para a consciência da diversidade de experiências que devem ser somadas em prol do coletivo e para a compreensão fundamental do meio ambiente e dos problemas a ele relacionados;

Contribuir para o comprometimento das pessoas com os valores ambientais, participando ativamente de projetos coletivos;

Conscientizar de que o verdadeiro objetivo do desenvolvimento é melhorar a qualidade de vida das pessoas. E o desenvolvimento só será verdadeiro quando melhorar nossa vida e a Educação Ambiental deve estar direcionada para este objetivo.

Como bem retrata Silva Filho (2013)

É preciso fomentar uma educação ambiental dos próprios agentes, uma mudança de habitus, para que o resultado das lides que envolvam o meio ambiente tragam, com tintas fortes, aquilo que se espera de uma sociedade que respeite o vínculo-limite entre o homem e a natureza. Não há dúvida que se trata um de jogo de potentes interesses, onde os dominantes não irão declinar de suas posições e visões do direito.

Deste modo, pressupõe-se que a valoração da atividade artesanal dos pescadores advém de um trabalho de conscientização, não apenas de valores "verdes", como ressalta Guimarães (1995), mas questionando-se os valores já estabelecidos e propagados pela sociedade. Neste aspecto, pertine aos indivíduos que vislumbram a importância da Educação Ambiental, ao compreenderem que, para a plena efetivação da conexão entre um meio ambiente livre do domínio mercantil e pescadores conscientes da sua importância, é necessário lhes dar espaço, para que estes protagonizem e propaguem suas ideias e experiências à sociedade.

Assim, entendendo a necessidade de uma oposição ao poder dominante posto, no intuito de que os e as pescadoras artesanais alcancem, conforme a construção de sua percepção, a importância do diálogo crítico com os demais setores da sociedade, a partir da emancipação social de cada homem e mulher que exerça a atividade, de forma que lhe seja possível, compreendendo que possui não apenas um papel a representar, mas que pode protagonizar sua própria crítica. Assim, os sujeitos necessitam despertar a consciência de 
classe, para que tal representação seja percebida e então construída no íntimo de cada homem e mulher. $\mathrm{Na}$ realidade, é por meio de uma atividade educadora que se possibilitará o crescimento ou surgimento de uma percepção sobre o que se manifesta no meio, de forma que assim, cada sujeito impulsione o coletivo e o coletivo questione o sujeito, no intuito de se consolidar ou formalizar uma comunidade que se represente, com ou sem entidade de classe, colônia ou associação.

\section{Referências}

BRASIL. Decreto Lei $n^{\circ} 2.848$, de 7 de Dezembro de 1941. Disponível em: http://www.planalto.gov.br/ccivil_03/decreto-lei/Del2848compilado.htm. Acesso em: 20 Set. 2018.

BRASIL. Decreto $n^{\circ} 73.497$, de 17 de Janeiro de 1974. Disponível em: http://www2.camara.leg.br/legin/fed/decret/1970-1979/decreto-73497-17-janeiro-1974422018-publicacaooriginal-1-pe.html. Acesso em: 20 Set. 2018.

BRASIL. Constituição da República Federativa do Brasil de 1988. Disponível em: http://www.planalto.gov.br/ccivil_03/Constituicao/ConstituicaoCompilado.htm. Acesso em .Acesso em: 20 Set. 2018.

BRASIL. Lei 9.784, de 29 de Janeiro de1999. Regula o processo administrativo no âmbito da Administração Pública Federal. Disponível em: Acesso em: http://www.planalto.gov.br/ccivil_03/LEIS/L9784.htm. Acesso em: 20 Set. 2018.

BRASIL. Lei $n^{o} 10.779$, de 25 de Novembro de 2003. Dispõe sobre a concessão do benefício de seguro desemprego, durante o período de defeso, ao pescador profissional que exerce a atividade pesqueira de forma artesanal. Disponível em: http://www.planalto.gov.br/ccivil_03/LEIS/2003/L10.779.htm. Acesso em: 20 Set. 2018.

BRASIL. Instrução Normativa $n^{\circ}$ 197, de 2 de Outubro de 2008. Disponível em: http://pesquisa.in.gov.br/imprensa/jsp/visualiza/index.jsp?jornal=1\&pagina=92\&data=03/10 12008. Acesso em: 20 Set. 2018.

BRASIL. Lei $n^{\circ} 11.959$, de 29 de Junho de 2009. Dispõe sobre a Política Nacional de Desenvolvimento Sustentável da Aquicultura e da Pesca, regula as atividades pesqueiras,

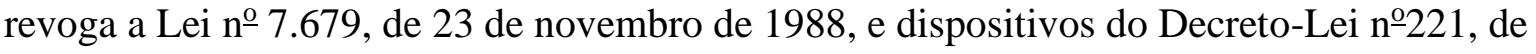
28 de fevereiro de 1967, e dá outras providências. Disponível em: http://www.planalto.gov.br/ccivil_03/_Ato2007-2010/2009/Lei/L11959.htm\#art37. Acesso em: 20 Set. 2018.

BRASIL. Memorando Circular $n^{\circ}$ 01/2015 - DRPA/SEMOC/MPA. A inserção de dados para fins de emissão de licença de pescador profissional artesanal no Sistema Informatizado do Registro Geral da Atividade Pesqueira - SisRGP foi suspensa conforme Memorando Circular $n^{\circ}$ 01/2015 - DRPA/SEMOC/MPA datado de 07.01.2015. Disponível em: http://www.consultaesic.cgu.gov.br/busca/dados/Lists/Pedido/Item/displayifs.aspx?List=0c8 39f31-47d7-4485-ab65-ab0cee9cf8fe \&ID=470701\&Web=88cc5f44-8cfe-4964-8ff4376b5ebb3bef. Acesso em 20 Set. 2018. 
BRASIL. Decreto $n^{\circ} 8.425$, de 31 de Março De 2015. Regulamenta o parágrafo único do art. 24 e o art. 25 da Lei ${ }^{\circ} 11.959$, de 29 de junho de 2009, para dispor sobre os critérios para inscrição no Registro Geral da Atividade Pesqueira e para a concessão de autorização, permissão ou licença para o exercício da atividade pesqueira. Disponível em:

http://www.planalto.gov.br/ccivil_03/_Ato2015-2018/2015/Decreto/D8425.htm. Acesso em: 20 Set. 2018.

BRASIL. Portaria n $n^{\circ}$ 1.275-Sei, de 26 de Julho de 2017. Disponível em: http://portal.imprensanacional.gov.br/materia/lasset_publisher/Kujrw0TZC2Mb/content/id/19199432/do1-2017-07-27-portaria-n-1-275sei-de-26-de-julho-de-2017-19199415. Acesso em 20 Set. 2018.

BRASIL. Portaria $n^{o}$ 2.078-SEI, de 18 de Outubro de 2017. Disponível em: http://imprensanacional.gov.br/materia//asset_publisher/Kujrw0TZC2Mb/content/id/19364572/do1-2017-10-20-portaria-n-2-078sei-de-18-de-outubro-de-2017-19364519. Acesso em 20 Set. 2018.

BRASIL. Portaria $n^{o}$ 2. 2.546-SEI, de 29 de Dezembro de 2017. Regula a autorização temporária da atividade pesqueira, na categoria do Pescador Profissional Artesanal, até a finalização do recadastramento geral do Registro Geral da Atividade Pesqueira. Disponível em:

http://pesquisa.in.gov.br/imprensa/jsp/visualiza/index.jsp?data=09/01/2018\&jornal=515\&pa gina $=20 \&$ totalArquivos $=30$. Acesso em 20 Set. 2018.

BRASIL. Instrução Normativa $n^{\circ}$ 6, de 20 de Agosto de 2018. Dispõe sobre os procedimentos administrativos para a inscrição de pessoas físicas no Registro Geral da Atividade Pesqueira na categoria de Pescador Profissional no âmbito do MPA. Disponível em: http://www.imprensanacional.gov.br/materia//asset_publisher/Kujrw0TZC2Mb/content/id/37595262/do1-2018-08-21-instrucaonormativa-n-6-de-20-de-agosto-de-2018-37595020. Acesso em 20 Set. 2018.

GUIMARÃES, Mauro. A Dimensão Ambiental na Educação. Campinas: Papirus, 1995.

JUSTO, Felipe da Silva; AMORIM, Filipi Vieira. Aproximações entre legislação, pesca artesanal e educação ambiental. Revista Caribeña de Ciencias Sociales (abril 2019). Disponível em <https://www.eumed.net/rev/caribe/2019/04/legislacao-pescaeducacion.html>. Acesso em: 05 mai 2019.

MÜLLER, Jackson. Educação Ambiental: diretrizes para a prática pedagógica. Porto Alegre: Famurs, 2001.

REIGOTA, Marcos. O que é educação ambiental. São Paulo: Brasiliense, 2009. 